\title{
Fungi Recorded on Folivorous Lepidoptera: High Diversity Despite Moderate Prevalence
}

\author{
Robin Gielen $^{1, *(\mathbb{D}) \text {, Hendrik Meister }}{ }^{1}$, Toomas Tammaru ${ }^{1}$ and Kadri Põldmaa ${ }^{2}$ (D) \\ 1 Entomology Unit, Department of Zoology, Institute of Ecology and Earth Sciences, Faculty of Science and \\ Technology, University of Tartu, Vanemuise 46, Tartu 51014, Estonia; hendrik.meister@gmail.com (H.M.); \\ toomas.tammaru@ut.ee (T.T.) \\ 2 Mycology Unit, Department of Botany, Institute of Ecology and Earth Sciences, Faculty of Science and \\ Technology, University of Tartu, Ravila 14a, Tartu 50411, Estonia; hypomyc@ut.ee \\ * Correspondence: robin.gielen@ut.ee
}

Citation: Gielen, R.; Meister, H.; Tammaru, T.; Põldmaa, K. Fungi Recorded on Folivorous Lepidoptera: High Diversity Despite Moderate Prevalence. J. Fungi 2021, 7, 25. https://doi.org/10.3390/jof7010025

Received: 28 November 2020 Accepted: 29 December 2020 Published: 5 January 2021

Publisher's Note: MDPI stays neutral with regard to jurisdictional clai$\mathrm{ms}$ in published maps and institutional affiliations.

Copyright: (C) 2021 by the authors. Licensee MDPI, Basel, Switzerland. This article is an open access article distributed under the terms and conditions of the Creative Commons Attribution (CC BY) license (https:// creativecommons.org/licenses/by/ $4.0 /)$.

\begin{abstract}
The knowledge about the diversity and ecological role of entomopathogenic fungi is primarily based on agroecosystems whereas information derived from natural insect populations is much more limited. To contribute to filling this gap, we recorded the prevalence of fungal infections in laboratory rearing experiments with five species of Lepidoptera, and in a field rearing experiment including one of these moths. The diversity of detected fungi was found to be high; we isolated 25 species of fungi from insects that had died in the course of these experiments. Six species belonged to the family Cordycipitaceae known to include unambiguous insect pathogens. The trophic niche of the representatives of other taxa is less clear and requires further studies. Regarding the most abundant species, Cordyceps farinosa, in which this question could be addressed, there was no indication of specialization on particular insect hosts, whereas several of the less common species may have been recorded from lepidopteran hosts for the first time. Across the subsets of the data, the prevalence of fungal infections generally remained below $5 \%$. Our results are thus consistent with the idea that entomopathogenic fungi are always present in insect populations but rarely reach epizootic levels. The detected species richness shows that much is to be gained from mapping the diversity of fungal species associated with folivorous insects in natural populations.
\end{abstract}

Keywords: Geometridae; Hypocreales; mortality; moth; larva; pupa; entomopathogen

\section{Introduction}

Focusing on the interactions of insects with plants and microbes has been considered the key to better understand various mechanisms behind ecosystem functioning [1]. The significance of insects is modulated by their abundance and the diversity of biotic interactions, most prominently of those with various natural enemies. As insects cause great losses in forestry and agriculture, the understanding of the biology of their natural enemies is of high importance also in the applied context [2-4]. Thus far, parasitoids and vertebrates have received most research effort in the context of ecological studies on insects $[5,6]$. Naturally, pathogens have also not escaped attention as antagonists of insects [7-9]; among those, viruses have had a central role in ecological studies [10]. Moreover, from the late 1990s, there has been an exponential growth in studies focusing on the use of fungi as biocontrol agents [2,11]. However, the knowledge about the role of entomopathogenic fungi in natural settings is still scarce, despite the almost two centuries long awareness about these organisms in the scientific community [12].

To contribute to filling this gap, we recorded the diversity and prevalence of lethal fungal pathogens in laboratory rearing of lepidopteran larvae that represented offspring of field-collected females, fed with field-collected host plants. The assemblage of fungal pathogens in the laboratory was compared to that recorded in a field experiment in which 
moth larvae were reared in a seminatural setting. The focus was set on plant- and airborne fungal infections relevant for folivorous larvae, with the interactions of soil-dwelling pupae [2,3] remaining beyond the scope of the present paper. We discuss the patterns of diversity and abundance of insect-associated fungi on lepidopteran hosts, and report taxa not recorded on this group of insects previously.

\section{Materials and Methods}

\subsection{Laboratory Rearing}

Data on fungal pathogens present in laboratory rearing of Lepidoptera were obtained as a by-product of ecological experiments performed at the University of Tartu, Estonia, in 2014-2017. Four lepidopteran species-Ematurga atomaria L., Cabera pusaria L., Hypomecis punctinalis Scopoli (Geometridae), and Orthosia gothica L. (Noctuidae)—were subjected to identical experimental design ([13-15], and unpublished). Specifically, in order to record growth rates, developmental periods, and final weights, we reared the larvae from eggs to pupae singly in $50 \mathrm{~mL}$ plastic vials at different temperatures and weighed them periodically. Within each combination of year and species, the insects were reared simultaneously under common garden design, while the timing of experiments with different species did not coincide due to natural phenological differences of the insects. The data on the fifth species, Chiasmia clathrata L. (Geometridae), were obtained from a technically similar study in which growth parameters of selection lines were compared (Välimäki et al., unpublished). The larvae were fed with leaves of host plants collected in the field in Tartu, or surroundings of the town. The larvae of E. atomaria were fed on Trifolium repens L. (Fabaceae), Vaccinium myrtillus L. (Ericaceae) and Salix alba L. (Salicaceae); C. pusaria on Alnus glutinosa (L.) Gaertn. (Betulaceae); H. punctinalis on Betula pendula Roth. (Betulaceae), Tilia cordata Mill. (Tiliaceae), and Quercus robur L. (Fagaceae); O. gothica on B. pendula; and C. clathrata on Lathyrus pratensis L. (Fabaceae).

The larvae were allowed to pupate in moist Sphagnum moss, known for its antiseptic properties. This should have minimized the insects' risk of being infected during the pupal period, allowing us to focus on infections acquired during the larval stage. The pupae were kept overwinter in thermoregulated chambers at about $0{ }^{\circ} \mathrm{C}$. In spring, adult moths were allowed to eclose at room temperature. The pupae that failed to eclose and eventually died were inspected for visual signs of fungal infection.

\subsection{Field Experiment}

To record the community of insect-associated fungi in near natural conditions, we reared larvae of $C$. pusaria on living wild host plants in mixed forest fragments in the surroundings of Tartu (between $58^{\circ} 26^{\prime} \mathrm{N}, 26^{\circ} 30^{\prime} \mathrm{E}$ and $58^{\circ} 24^{\prime} \mathrm{N}, 26^{\circ} 39^{\prime} \mathrm{E}$ ), Estonia, in the course of 2 years. Newly hatched larvae were enclosed in $50 \times 30 \mathrm{~cm}^{2}$ polyester bags $(N=81)$, in which they remained until pupation. Ten larvae per bag were placed on 3 different host plants of the moth-grey alder (Alnus incana (L.) Moench), silver birch (Betula pendula Roth.), and downy birch (B. pubescens Ehrh.) - in the first half of July 2016 and 2017 and were checked weekly for pupation. After pupation, the insects were placed individually into Empera $124 \mathrm{~N}$ polystyrene vials with sterilized peat moss (Sphagnum sp.). The moss was sterilized by keeping it at $100{ }^{\circ} \mathrm{C}$ for $4 \mathrm{~h}$. Vials were sterilized with $10 \%$ $\mathrm{NaOCl}$. Pupae overwintered in thermoregulated chambers at $2{ }^{\circ} \mathrm{C}$ for 3 months. In January, adult moths were allowed to eclose at $24^{\circ} \mathrm{C}$ and $12: 12 \mathrm{~h}$ of light/darkness cycle. Insects that died during the pupal period were inspected for visual signs of fungal infection.

\subsection{Identification of Fungi and Their Host Ranges}

To identify the fungi and preserve these as pure living cultures, we inoculated visible fungal material (only anamorphs were encountered) to Petri dishes with $2 \%$ malt extract agar (Oxoid, Cambridge, UK) supplemented with antibiotics (1\% of streptomycin and tetracycline). After a few weeks of growth in culture, the fungi were identified on the basis of morphological traits using keys provided by Domsch et al. [16], Samson et al. [12], and 
Seifert et al. [17]. A culture isolate representing each morphotype was subjected to DNA extraction to confirm the identification.

The procedures of growing the mycelium, extracting DNA, conducting PCR, and sequencing followed the protocols described by Põldmaa et al. [18]. Ribosomal DNA full ITS and partial LSU sequences were obtained from 91 fungal isolates. The sequences along with their metadata were uploaded in PlutoF, a data management and publishing platform [19], and made available via UNITE database [20]. The ITS rDNA sequences were incorporated in the UNITE species hypotheses (SH), which served as the basis for species identification, by choosing an appropriate distance threshold value in each case (Table 1). The Basic Local Alignment Search Tool (blastn) at National Centre for Biotechnology Information [21] was used to check for similar sequences not yet incorporated in the UNITE database.

Table 1. Species of fungi isolated from lepidopteran hosts (the field experiment data in brackets). UNITE species hypothesis (SH) codes are presented to facilitate communication on detected fungi [22].

\begin{tabular}{|c|c|c|c|}
\hline Order/Family & Species & SH DOI * & Hosts ** \\
\hline \multirow[t]{6}{*}{ Hypocreales/Cordycipitaceae } & $\begin{array}{c}\text { Akanthomyces muscarius (Petch) Spatafora, } \\
\text { Kepler \& B. Shrestha }\end{array}$ & SH1886969.08FU & $\begin{array}{c}\text { EA } 8 \\
\text { CP } 4(+25) \\
\text { HP } 1\end{array}$ \\
\hline & Cordyceps bifusispora O.E. Erikss. & SH1887323.08FU & $\begin{array}{c}\text { CP (2) } \\
\text { EA } 1 \\
\text { EA } 29\end{array}$ \\
\hline & $\begin{array}{c}\text { Cordyceps farinosa (Holmsk.) Kepler, B. } \\
\text { Shrestha \& Spatafora }\end{array}$ & SH1524463.08FU & $\begin{array}{c}\text { CP } 6(+10) \\
\text { HP } 7 \\
\text { UP } 1\end{array}$ \\
\hline & Lecanicillium praecognitum Gorczak \& Kisło & SH1524455.08FU & $\begin{array}{l}\text { CC } 1 \\
\text { EA } 4\end{array}$ \\
\hline & Simplicillium aogashimaense Nonaka, Kaifuch i \& Masuma & SH1988378.08FU & EA 1 \\
\hline & Simplicillium lanosoniveum (J.F.H Beyma) Zare \& W. Gams & SH1988383.08FU & $\begin{array}{l}\text { OG } 1 \\
\text { HP } 1\end{array}$ \\
\hline Clavicipitaceae & $\begin{array}{c}\text { Metapochonia bulbillosa (W.Gams \& Malla) Kepler, } \\
\text { S.A.Rehner \& Humber }\end{array}$ & SH1930500.08FU & $\begin{array}{l}\text { CP } 1(+2) \\
\text { EA } 1\end{array}$ \\
\hline \multirow[t]{4}{*}{ Hypocreaceae } & $\begin{array}{c}\text { Trichoderma cf. aethiopicum Mullaw, C.P. } \\
\text { Kubicek \& Samuels }\end{array}$ & SH1568015.08FU & $\mathrm{CP}(7)$ \\
\hline & Trichoderma koningii Oudem. & SH2303517.08FU & $\begin{array}{l}\text { CP } 1 \\
\text { EA } 1\end{array}$ \\
\hline & Trichoderma trixiae/virilente/viridescens & SH2303501.08FU & $\mathrm{CP} 1$ \\
\hline & Trichoderma viride Pers. & SH2303512.08FU & EA 1 \\
\hline & Fusarium cf. sporotrichioides Sherb. & SH2456045.08FU & $\begin{array}{l}\text { EA } 1 \\
\text { OG } 1\end{array}$ \\
\hline & Fusarium solani species complex & SH2228332.08FU & $\begin{array}{l}\text { HP } 1 \\
\text { EA } 2\end{array}$ \\
\hline & Fusarium tricinctum (Corda) Sacc. & SH1919083.08FU & $\begin{array}{l}\mathrm{HP} 1 \\
\mathrm{CP}(5)\end{array}$ \\
\hline Tilachlidiaceae & Tilachlidium brachiatum (Batsch) Petch & SH1513367.08FU & $\begin{array}{l}\text { CC } 1 \\
\text { EA } 2\end{array}$ \\
\hline \multirow[t]{3}{*}{ Eurotiales / Aspergillaceae } & Penicillium thomii Maire & SH2189918.08FU & $\begin{array}{l}\text { EA } 1 \\
\text { CP (12) } \\
\text { CP } 1\end{array}$ \\
\hline & Penicillium sp. & SH2283940.08FU & $\begin{array}{l}\text { EA } 4 \\
\text { UP } 1\end{array}$ \\
\hline & Penicillium paczoskii K.W. Zaleski & SH2189912.08FU & $\mathrm{CP} 1$ \\
\hline Dothideales/Saccotheciaceae & Aureobasidium pullulans (de Bary) G. Arnaud & SH1872652.08FU & EA 2 \\
\hline Capnodiales/Cladosporiaceae & Cladosporium delicatulum Link & SH2320203.08FU & HP 1 \\
\hline \multirow[t]{2}{*}{ Mucorales/Mucoraceae } & Mucor hiemalis Wehmer & SH1989679.08FU & CP (17) \\
\hline & Mucor plumbeus Bonord. & - & $\mathrm{CP}(25)$ \\
\hline Mortierellales/Mortierellaceae & Mortierella humilis Linnem. ex W. Gams & SH2444324.08FU & $\begin{array}{l}\text { EA } 4 \\
\text { CP }(1)\end{array}$ \\
\hline Umbelopsidales/Umbelopsidac & Umbelopsis sp. & - & EA 1 \\
\hline
\end{tabular}

${ }^{*} \mathrm{DOI}=$ digital object identifier, $\mathrm{SH}$ DOI is displayed here as a short code; ${ }^{* *}$ insect hosts abbreviated as EA-Ematurga atomaria, $\mathrm{CP}-$ Cabera pusaria, $\mathrm{HP} —$ Hypomecis punctinalis, CC—Chiasmia clathrata, OP—Orthosia gothica, UP—unidentified pupa. 
All pupae infected with a fungus were deposited at the TU fungarium (accession numbers TU133001-133196) and representative isolates at the TFC culture collection (TFC202234202344) in the Natural History Museum and Botanical Garden, University of Tartu.

\section{Results}

\subsection{Fungi from the Laboratory Experiments and Their Prevalence}

Data on 2978 lepidopteran pupae were obtained from the laboratory rearing experiments (Table 2). Fungi were detected from 82 pupae $(2.8 \%)$ and identified as representing 23 species from 10 families and 6 orders (Table 1). The prevalence of fungal infections differed among the 3 years but remained below $10 \%$ (Table 2, note the small sample sizes of C. pusaria and H. punctinalis in 2016, associated with atypically high prevalence). The majority of the fungi belonged to Cordycipitaceae (59 pupae infected), followed by Aspergillaceae (8), Nectriaceae (7), Mortierellaceae (4), Hypocreaceae (4), Tilachlidiaceae (3), Clavicipitaceae (2), Saccotechiaceae (2), Umbelopsidaceae (1), and Cladosporiaceae (1).

Table 2. Incidence of fungal infection in lab reared moths in different years.

\begin{tabular}{cccc}
\hline Host Species & Year & Pupae & Fungal Prevalence \% \\
\hline Ematurga atomaria & 2014 & 383 & 2.3 \\
& 2015 & 327 & 5.2 \\
Cabera pusaria & 2016 & 554 & 6 \\
& 2014 & 179 & 0 \\
Chiasmia clathrata & 2015 & 286 & 3.1 \\
Orthosia gothica & 2016 & 13 & 53.8 \\
Hypomecis punctinalis & 2014 & 409 & 0.5 \\
& 2014 & 462 & 0.4 \\
& 2015 & 360 & 1.7 \\
\hline
\end{tabular}

On the basis of previous knowledge [12], all of the Cordycipitaceae (six species, overall prevalence $2.2 \%$ ) were considered to unambiguously represent entomopathogens infecting living hosts. The most abundant of such species, Cordyceps farinosa, was found in total on 43 pupae of 3 moth species out of 5 . While present each year, it was the most prevalent entomopathogen in 2015 and 2016. Species from other families should be considered potential (opportunistic) pathogens of Lepidoptera as most of them belong to large genera including saprotrophs and pathogens of various hosts, with some representatives occasionally found also on insects [23-25]. There are exceptions from this general scheme, however. In particular, while several species of Clavicipitaceae are known as entomopathogens, the genus Metapochonia has been mainly found on nematodes. The genus is represented here by the nematode and rotifer pathogen Metapochonia bulbillosa [26], whereas the respective UNITE SH (Table 1) also includes a few sequences obtained from Coleoptera. Moreover, Tilachlidium brachiatum has been known to grow only on decaying fungi (K. Põldmaa, personal observation). In addition, our data may include the first records on Lepidoptera/insects for some species from the genera Mariannaea, Mortierella, Simplicillium, Trichoderma, and Umbelopsis. However, the respective host associations need further investigation as species concepts in these groups are changing as a consequence of advances in molecular systematics.

Lepidopteran species differed in the prevalence of infection-O. gothica had the lowest rate $(0.4 \%)$, while E. atomaria and C. pusaria had the highest ( $5 \%$ and $3.3 \%$, respectively). There was also a difference between the 3 years of study, showing a trend of increase in the fungal prevalence (Table 2). However, given the somewhat non-systematic character of the data (rearing experiments were not designed to study the prevalence of infections), we refrain here from presenting formal statistical analyses. 


\subsection{Field Experiment}

Of the 868 first instar C. pusaria caterpillars released for the experiment, 296 (34.1\%, Table 3) insects reached pupation. Fungi were detected on 87 out of the 191 dead pupae $(45.5 \%)$. However, if we consider only Cordycipitaceae ( 3 species on 37 pupae), the average prevalence of fungal infections drops to $17.3 \%$ (2.2\% in 2016 and $24 \%$ in 2017). The prevalence of fungi was thus considerably higher in the field compared to the lab rearings. The detected taxa (10 species, Table 1) overlapped with those that were identified in the laboratory rearing, except for two species of Mucorales, known as ubiquitous saprotrophs (but see also [24]). The 19 pupae, infected by a member of Cordycipitaceae plus another fungus, suggest that the latter may represent saprotrophs exploiting the already dead moth tissue.

Table 3. Demographic parameters of C. pusaria in the field experiment. Total sample size is shown in brackets.

\begin{tabular}{cccc}
\hline \multirow{2}{*}{ Year } & \multirow{2}{*}{ Survived until Pupation } & \multicolumn{2}{c}{ Pupal Mortality } \\
\cline { 3 - 4 } & & Fungi & Cause Unknown \\
\hline 2016 & $55.7 \%(140)$ & $13.3 \%(45)$ & $86.7 \%(45)$ \\
2017 & $29.9 \%(728)$ & $55.5 \%(146)$ & $44.5 \%(146)$ \\
\hline
\end{tabular}

\section{Discussion}

Our results suggest that potentially entomopathogenic fungi are invariably present in insect populations. Fungal infections were recorded in all subsets of our laboratory rearing data (host species * year), with just one exception (C. pusaria in 2014, but note the low samples size, Table 2). The detected diversity of fungi was notably high. Altogether, 25 species of fungi from 7 orders were isolated from the laboratory and the field experiments, with two-thirds (16 species) belonging to the Hypocreales (Table 1). Six of the collected fungi could not be unambiguously affiliated to a described species on the basis of their ITS DNA sequences (Table 1), and UNITE species hypotheses with respective DOI codes [22] are used for communicating on these. This might have been due to the possibility that cryptic undescribed species were involved, or that voucher specimens of known species have not yet been sequenced, or the inapplicability of the ITS region for discriminating sibling species. Greatest fungal diversity was found on Ematurga atomaria (17 spp.), followed by Cabera pusaria (11), Hypomecis punctinalis (6), Chiasmia clathrata (2), and Orthosia gothica (2). However, the numbers of species recorded for each host are well consistent with species-specific sample sizes (Table 2) so that these figures should not be interpreted as an indication of differences in the community of fungi associated with different moth species.

Among the unambiguously entomopathogenic fungi, here defined as members of Cordycipitaceae, we identified two abundant (Akanthomyces muscarius and Cordyceps farinosa) and five scarce species (Table 1). In addition, members of the families Hypocreaceae, Nectriaceae, Aspergillaceae, and Mucoraceae were frequently found growing on dead insect pupae. These fungi were especially common in the field experiment, often accompanying a species of the Cordycipitaceae. Therefore, we may consider such fungi to primarily take advantage of pupae killed by other pathogens, but it cannot by any means be excluded that some of these may still possess thus far unrecognized opportunistic abilities to cause the death of the insects (see [24]). Further studies are needed to establish the nutritional strategies of fungi that are repeatedly found on dead insects.

Our study focused on fungal infections of folivorous larvae, which can only be brought about by plant- and air-borne propagules. In particular, the hosts were not in contact with soil and leaf litter, which are the environments considered to constitute reservoirs for entomopathogenic fungi $[2,4]$. This may explain why our samples did not include some well-known and common entomopathogens, such as Beauveria and Metarhizium spp., and suggests that the full spectrum of the fungi associated with natural populations of the 
studied insects may be considerably broader than recorded in the present study. Several of the presumable saprotrophs/potential entomopathogens, for which we have identified no or just very few previous records on insects, have been reported from plants, soil, or also from air and water. The fact that such fungi were more common on pupae from the field than from the lab experiment suggests that prolonged exposure to the natural environment favors the deposition of different fungi on insects and/or their host plants (but see also [2]).

Our laboratory-derived data do not suggest any strong specialization of the fungi to particular host species. However, the just moderate amount of data available did not allow us to perform any formal analyses of specialization patterns. Indeed, 9 of the 13 fungal species that were found only on one host were represented by just a single observation. Nevertheless, it should be noted that the most abundant species-Cordyceps farinosa and Akanthomyces muscarius - were both found as readily infecting all the three most numerous hosts (C. pusaria, E. atomaria, and H. punctinalis), with no evidence of preferring one species over the other.

The overall prevalence of fungal infections in our laboratory rearings varied among different subsets of the data from 0 to $6 \%$ (excluding subsamples with less than 100 pupae). This value was 13.3 and $55.5 \%$ for the 2 years of the field experiment ( 0 to $6 \%$ vs. 2.2 and $24 \%$, if to consider Cordycipitaceae only), indicating 10 times higher incidence of fungal infections than in the laboratory rearings. These values of prevalence can alone be interpreted as evidence of a non-negligible role of the insect-fungus interactions in the ecology of studied moths.

The lab-based estimates can underestimate the prevalence of entomopathogens in nature as the insects in the laboratory culture should be less exposed to various potential sources of infection than in the field, e.g., soil or infected insects $[23,27]$. Alternatively, laboratory mass rearings of insects might be prone to disease outbreaks, leading to higher prevalence values in the lab compared to the field. This appears not to have been the case, as epizootic levels were not reached in any of the subsets of our data. Additionally, the diversity of fungal pathogens recorded in the lab, as well as their similarity with field collections, provides evidence against outbreak of a particular fungus in our experimental facilities. The observation that fungal pathogens are always present at low frequencies is well consistent with the decades-long experience of insect rearing by some of the authors (but see [28]). Such a pattern might indicate that the presence of fungal conidia is not a limiting determinant of the prevalence of fungal diseases (see also [29]) but instead, the condition of the host may be decisive-only the weakest individuals are unable to resist the infection $[4,30]$.

Currently, ecological knowledge about entomopathogenic fungi is primarily based on studying a few well-known species of fungi and isolating entomopathogens mainly from soil rather than describing complete fungal communities of particular insect species [3]. This has produced a skew in our knowledge, with the conclusions mainly based on a few members of the Hypocreales such as Beauveria and Metarhizium species [8]. The present study is one of the first that has aimed to document a full set of fungi isolated from several lepidopteran species (see also [24,25]). The detected diversity should inspire further studies - in addition to considerable bionomic data to be gained, the deeper knowledge would allow us to address the thus far little understood ecological role of pathogenic fungi in natural insect populations.

Author Contributions: Conceptualization, K.P., T.T., and R.G.; methodology, K.P., T.T., and H.M.; investigation, R.G. and H.M.; data curation, R.G. and H.M.; writing-R.G., T.T., and K.P. All authors have read and agreed to the published version of the manuscript.

Funding: This research was funded by the Estonian Research Council grants PRG741 and IUT20-30 and the European Union through the European Regional Development Fund (the Center of Excellence EcolChange).

Conflicts of Interest: The authors declare no conflict of interest. 


\section{References}

1. Yang, L.H.; Gratton, C. Insects as drivers of ecosystem processes. Curr. Opin. Insect Sci. 2014, 2, 26-32. [CrossRef]

2. Goettel, M.S.; Eilenberg, J.; Glare, T. Entomopathogenic fungi and their role in regulation of insect populations. In Insect Control, Biological and Synthetic Agents; Glibert, L.I., Gill, S.S., Eds.; Elsevier: Amsterdam, The Netherlands, 2010 ; pp. $361-405$. ISBN 978-0-12-381449-4.

3. Hesketh, H.; Roy, H.E.; Eilenberg, J.; Pell, J.K.; Hails, R.S. Challenges in modelling complexity of fungal entomopathogens in semi-natural populations of insects. BioControl 2010, 55, 55-73. [CrossRef]

4. Augustyniuk-Kram, A.; Kram, K.J. Entomopathogenic fungi as an important natural regulator of insect outbreaks in forests (Review). In Forest Ecosystems-More than Just Trees; Blanco, J.A., Lo, Y.-H., Eds.; IntechOpen: London, UK, $2012 ;$ pp. 265-294. ISBN 978-953-51-0202-1.

5. Cory, J.S.; Hoover, K. Plant-mediated effects in insect-pathogen interactions. Trends Ecol. Evol. 2006, 21, 278-286. [CrossRef] [PubMed]

6. Price, P.W.; Denno, R.F.; Eubanks, M.D.; Finke, D.L.; Kaplan, I. Insect Ecology: Behavior, Populations and Communities; Cambridge University Press: Cambridge, UK, 2011; ISBN 978-1-139-50443-0.

7. Hajek, A.E.; McManus, M.L.; Delalibera, I. A review of introductions of pathogens and nematodes for classical biological control of insects and mites. Biol. Control 2007, 41, 1-13. [CrossRef]

8. Sánchez-Bayo, F.; Wyckhuys, K.A.G. Worldwide decline of the entomofauna: A review of its drivers. Biol. Conserv. 2019, 232, 8-27. [CrossRef]

9. Dwyer, G.; Elkinton, J.S. Using simple models to predict virus epizootics in gypsy moth populations. J. Anim. Ecol. 1993, 62, 1-11. [CrossRef]

10. Sparks, W.O.; Bartholomay, L.C.; Bonning, B.C. Insect immunity to viruses. In Insect Immunology; Elsevier: Amsterdam, The Netherlands, 2008; pp. 209-242. ISBN 978-0-12-373976-6.

11. De la Cruz Quiroz, R.; Cruz Maldonado, J.J.; de Rostro Alanis, M.J.; Torres, J.A.; Parra Saldívar, R. Fungi-based biopesticides: Shelf-life preservation technologies used in commercial products. J. Pest Sci. 2019, 92, 1003-1015. [CrossRef]

12. Samson, R.A.; Evans, H.C.; Latge, J.-P. Atlas of Entomopathogenic Fungi; Springer Science \& Business Media: Berlin, Germany, 2013; ISBN 978-3-662-05890-9.

13. Meister, H.; Esperk, T.; Välimäki, P.; Tammaru, T. Evaluating the role and measures of juvenile growth rate: Latitudinal variation in insect life histories. Oikos 2017, 126, 1726-1737. [CrossRef]

14. Meister, H.; Hämäläinen, H.R.; Valdma, D.; Martverk, M.; Tammaru, T. How to become larger: Ontogenetic basis of amongpopulation size differences in a moth. Entomol. Exp. Appl. 2018, 166, 4-16. [CrossRef]

15. Meister, H.; Tammaru, T.; Sandre, S.-L.; Freitak, D. Sources of variance in immunological traits: Evidence of congruent latitudinal trends across species. J. Exp. Biol. 2017, 220, 2606-2615. [CrossRef]

16. Domsch, K.H.; Gams, W.; Anderson, T.H. Compendium of Soil Fungi, 2nd ed.; Academic Press (London) Ltd.: London, UK, 2007; ISBN 978-3-930167-69-2.

17. Seifert, K.; Morgan-Jones, G.; Gams, W.; Kendrick, B. The Genera of Hyphomycetes; CBS-KNAW Fungal Biodiversity Centre: Utrecht, The Netherlands, 2011; ISBN 978-90-70351-85-4.

18. Põldmaa, K.; Bills, G.; Lewis, D.P.; Tamm, H. Taxonomy of the Sphaerostilbella broomeana-group (Hypocreales, Ascomycota). Mycol. Prog. 2019, 18,77-89. [CrossRef] [PubMed]

19. Abarenkov, K.; Tedersoo, L.; Nilsson, R.H.; Vellak, K.; Saar, I.; Veldre, V.; Parmasto, E.; Prous, M.; Aan, A.; Ots, M.; et al. PlutoF-A Web Based Workbench for Ecological and Taxonomic Research, with an Online Implementation for Fungal ITS Sequences. Evol. Bioinform. 2010. [CrossRef]

20. Kõljalg, U.; Nilsson, R.H.; Abarenkov, K.; Tedersoo, L.; Taylor, A.F.S.; Bahram, M.; Bates, S.T.; Bruns, T.D.; Bengtsson-Palme, J.; Callaghan, T.M.; et al. Towards a unified paradigm for sequence-based identification of fungi. Mol. Ecol. 2013, 22, 5271-5277. [CrossRef] [PubMed]

21. NCBI Resource Coordinators. Database resources of the National Center for Biotechnology Information. Nucleic Acids Res. 2016, 44, D7-D19. [CrossRef]

22. Kõljalg, U.; Nilsson, H.R.; Schigel, D.; Tedersoo, L.; Larsson, K.-H.; May, T.W.; Taylor, A.F.S.; Jeppesen, T.S.; Froslev, T.G.; Lindahl, B.D.; et al. The taxon hypothesis paradigm-On the unambiguous detection and communication of taxa. Microorganisms 2020, 8, 1910. [CrossRef]

23. Kryukov, V.Y.; Yaroslavtseva, O.N.; Lednev, G.R.; Borisov, B.A. Local Epizootics caused by teleomorphic cordycipitoid fungi (Ascomycota: Hypocreales) in populations of forest lepidopterans and sawflies of the summer-autumn complex in Siberia. Microbiology 2011, 80, 286-295. [CrossRef]

24. Poitevin, C.G.; Porsani, M.V.; Poltronieri, A.S.; Zawadneak, M.A.C.; Pimentel, I.C. Fungi isolated from insects in strawberry crops act as potential biological control agents of Duponchelia fovealis (Lepidoptera: Crambidae). Appl. Entomol. Zool. 2018, 53, 323-331. [CrossRef]

25. Glowacka-Pilot, B. Entomogenous bacteria and fungi occurring in caterpillars of the pine moth (Dendrolimus pini L.). Pr. IBL 1974, 427, 3-60.

26. Kepler, R.M.; Humber, R.A.; Bischoff, J.F.; Rehner, S.A. Clarification of generic and species boundaries for Metarhizium and related fungi through multigene phylogenetics. Mycologia 2014, 106, 811-829. [CrossRef] 
27. Mora, M.A.E.; Castilho, A.M.C.; Fraga, M.E. Classification and infection mechanism of entomopathogenic fungi. Arq. Inst. Biológico 2017, 84. [CrossRef]

28. Scholte, E.-J.; Knols, B.G.J.; Samson, R.A.; Takken, W. Entomopathogenic fungi for mosquito control: A review. J. Insect Sci. 2004, 4, 19. [CrossRef] [PubMed]

29. Lacey, J. 13-The aerobiology of conidial fungi. In Biology of Conidial Fungi; Cole, G.T., Kendrick, B., Eds.; Academic Press: Cambridge, MA, USA, 1981; pp. 373-416. ISBN 978-0-12-179501-6.

30. Castrillo, L.A. The host population. In Ecology of Invertebrate Diseases; Hajek, A.E., Shapiro-Ilan, D.I., Eds.; John Wiley \& Sons, Incorporated: Hoboken, NJ, USA, 2018; pp. 101-142. ISBN 978-1-119-25607-6. 